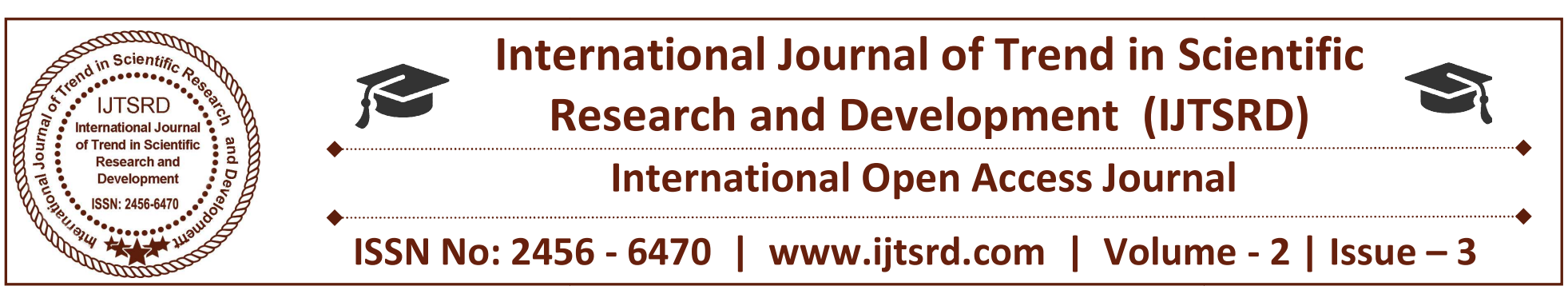

\title{
Rehabilitation of Buildings for Functional Unsuitability: Need of Structural Health Monitoring
}

\author{
Utkarsh Nigam \\ Assistant Professor, Govt. Engineering College \\ Jhalawar (NPIU Faculty), Rajasthan, India
}

\author{
Rajneesh Sharma \\ H.O.D. (Civil) \& Assistant Professor, Govt. \\ Engineering College Jhalawar, Rajasthan, India
}

\section{ABSTRACT}

Repair is the process of restoring something that is now damaged, brock or deteriorated to fair condition and good quality. Rehabilitation is defined as the process of improving and returning the building or structure or ground to its previous well condition. Repair and rehabilitation is useful tool to satisfy the buildings functional requirement. Any structure has to be structurally tough and functionally suitable for fulfilling the condition of good structure as per limit states. In the present study it is analyzed that how rehabilitation is insufficient for a structure sometimes if the building has not maintained properly after its construction. Some case studies of Older buildings has been taken in consideration and it is revealed that if the building have been kept in maintenance or the building could have been well monitored that its condition could be more better that present deteriorated condition. Any structure must be monitored for its health and suitability for time to time utility. Maintenance of the structure is an asset for monitoring. Various NDT techniques and visual inspections have been carried out to justify the suitability of structural health monitoring. It has been observed that after the construction the building is used to the utmost utility without considering the maintenance and monitoring which leads to sudden deterioration and damage. Efforts have been made to clarify the importance of repair, rehabilitation, deterioration, maintenance, health monitoring and corrosion for a building.

Keywords: Maintenance, NDT Techniques, Repair, Rehabilitation, Structural Health Monitoring

\section{INTRODUCTION}

Distress means visual appearance of building and structure seems improper as per aesthetic views and also it may be functionally unsuitable for the desired requirement. Buildings and structures are designed as per the limit state of collapse viz. bending, shear, torsion, flexure and limit state of serviceability viz deflection, vibrations etc. in which it is assumed that till the end of design life the building will sustain the loads and remains fit as per functional requirements.

Sometimes the buildings may even get unsuitable to use as per the functional requirements because though it may be suitable as per limit state of collapse but it may not be suitable for serviceability criteria. This lapse in serviceability requirements before or after design life of a structure leads to deterioration of buildings.

Maintenance of a building and structure is needed to keep the building in good condition. Practices of repairing and rehabilitation should be done to maintain it. Maintenance is defined as the art of keeping things in good conditions and or for structures it is meant for keeping the structure safe as per safety and serviceability criteria. Checking, prevention and repairs are the facets of maintenance.

\section{LITERATURE REVIEWS}

For carrying out study on the topic of rehabilitation and structural monitoring various books and articles were reviewed. R. Dodge Woodson (2009) in his book of repairs and rehabilitation mentions that repairing is very important especially for the older buildings and for buildings which becomes unsafe as 
per serviceability criteria. Manual on Repair and Rehabilitation of RCC Buildings, 2012 reflects that the concrete repairs and reinforced concrete repair has to be taken care from the stage of construction itself. Structural components and the materials used in structure must be good and used as per strength criteria. Condition Assessment of Buildings for Repair and Upgrading Prepared by CPWD also reveals that building must be assessed and monitored for its long term use.

Abhijitsinh Parmar (2014) in his book of rehabilitation of structures shows the different repair methods, techniques and causes of corrosion and cracks. It must be very fundamental to use a good quality cement and sand in concrete and also cement in concrete must be used as repair materials also. Modi and Patel (2015) in their book of repair and rehabilitation of concrete structure describes the phenomenon of distress, deterioration, causes of corrosion, cracks and different materials and repair techniques. In addition to these techniques he has reflected many other modern techniques also related to the structural health monitoring was depicted. It can be seen that the material used in structures along with concrete is highly predominant in the structures.

\section{CAUSES OF DETERIORATION \\ DISTRESS \\ AND}

"Durability of concrete is defined as its ability to resist weathering action, chemical attack, abrasion or any other process of deterioration. Durable concrete will retain its original form, quality and serviceability when exposed to environment." (ACI 201.2 R92). Repair and rehabilitation of deteriorated concrete is an art as well as a science.

1. Restore or improve structural integrity

2. Improve appearance

3. Improve durability

\section{Improve functional performance}

\section{Provide water-tightness}

Developing a proper repair strategy to address concrete problem requires an understanding of the CAUSE of the problem. Understanding the cause allows for a repair that addresses both cause and effect.

\section{Concrete Repair Process}

The concrete repair process involves cause/effect relationship, concrete evaluation, and analysis \& repair strategy. The steps are as follows: 1 . seeing an EFFECT, 2. determining the CAUSE 3. Deciding whether the problem needs to be repaired 4 . Conducting some form of condition survey to quantify problems 5 . Dealing with repair analysis and engineering issues in the repair 6. Determine repair strategies that include methods, techniques and repair materials 7. Finally, accomplishing the repair.

\section{Causes of Distress and Deterioration}

\begin{tabular}{|c|c|c|}
\hline $\begin{array}{l}\text { 1.Accidental } \\
\text { sudden Loads } \\
\text { 2. Chemical } \\
\text { Reasons } \\
\text { 2.1 Acid attack } \\
\text { 2.2Aggressive- } \\
\text { hydro attack } \\
\text { 2.3Alkali- } \\
\text { carbonate rock } \\
\text { reaction } \\
\text { 2.4Alkali-silica } \\
\text { 2.5Miscellaneous } \\
\text { other chemical } \\
\text { attack } \\
\text { 2.6Sulfate attack } \\
\text { 3. Construction } \\
\text { Faults }\end{array}$ & $\begin{array}{l}\text { 4.Corrosion in } \\
\text { present steel, } \\
\text { metals } \\
\text { 5.Design } \\
\text { Faults } \\
\text { 5.1 Inadequate } \\
\text { building design } \\
\text { 5.2Insufficient } \\
\text { design } \\
\text { detailing } \\
\text { 6.Erosion } \\
\text { 6.1Abrasion } \\
\text { 6.2 Cavitation } \\
\text { 7.F\&T } \\
\text { Abrasion } \\
\text { 8. Settlements } \\
\text { and } \\
\text { Movements }\end{array}$ & $\begin{array}{l}\text { 9.Shrinkage } \\
\text { and creep in } \\
\text { concrete } \\
\text { 9.1 Plastic } \\
\text { 9.2 Drying } \\
\text { 10.Thermal } \\
\text { Changes } \\
\text { (Temp.) } \\
\text { 10.1 Internal } \\
\text { 10.2 External } \\
\text { 10.3 Fire } \\
\text { 11. Weathering } \\
\text { or Decay }\end{array}$ \\
\hline
\end{tabular}

\section{Need for repairs and upgrading of structures,}

- Need of repairs and upgrading of structures is required due to many reasons. There are various a reason due to which repair is need which may be distress, distortion, deflection, deterioration, deficient strength.

- Repair is needed to increase the life of a structure, to increase strength or bearing capacity, to remove deflection and to ascertain fewer losses. Proper evaluation of concrete requires several steps. 
- The requirements for repairs or rehabilitation are generally established in one of three ways. In the worst case, there is a failure of structural integrity that prompts the need for an evaluation. Visual inspections often reveal a need for further evaluation and testing. If cracks, flaking, or other visual defects are encountered, a full investigation and evaluation are usually warranted. The third way to establish the need for an evaluation is periodic testing. This is the safest way to check the strength and dependability of concrete structures.

- If there is fault in design and construction of any concrete structure then it require repair. The repair technique or the method may differ and depend on the situation and detail of fault.

- A successful repair relies on many factors. One must consider the best repair strategy, material, and procedure. The best attempt at a repair is likely to fail if the wrong material is used for the repair.

- Whenever concrete repair is planned, one must consider options and then evaluate the proper type of material to use in the repair or rehabilitation of concrete structures.

You may find the choices for repair to be controversial in some venues. Appropriate experts may need to be consulted for ensured success. There are, however, many facts that are proven and can be trusted. They are what we are going to deal with in this chapter.

Repair of concrete is needed time to time as the structure gets old due to several reasons. We will discuss the steps involved in the process of repair of concrete structures. Following are the steps involved in the repair of damaged concrete:

\section{STEP 1: Determination of cause of Concrete defects:}

The first and important step for repairing a damaged concrete structure is to identify the causes responsible for the damage.

\section{STEP 2: Evaluation of extent of concrete damage:}

Evaluation of damage to concrete will help to understand the severity of damage and its effect on the life and serviceability of the structure.

\section{STEP 3: Evaluate the Need for Concrete Repair:}

Repair of concrete structural members required cost and time. So, it should be evaluated whether the structure needs the repair or can serve its intended purpose.

\section{STEP 4: Select the Concrete Repair Method}

\section{STEP 5: Prepare the Old Concrete for Repair:}

Preparation of the concrete for applying in the repair material is of primary importance in the accomplishment of durable repairs.

\section{STEP 6: Apply the Suitable Repair Method:}

There are many concrete repair methods and materials available based on type of damage. Suitable methods and materials should be used based on types of concrete damage.

\section{STEP 7: Cure the Concrete Repair Properly}




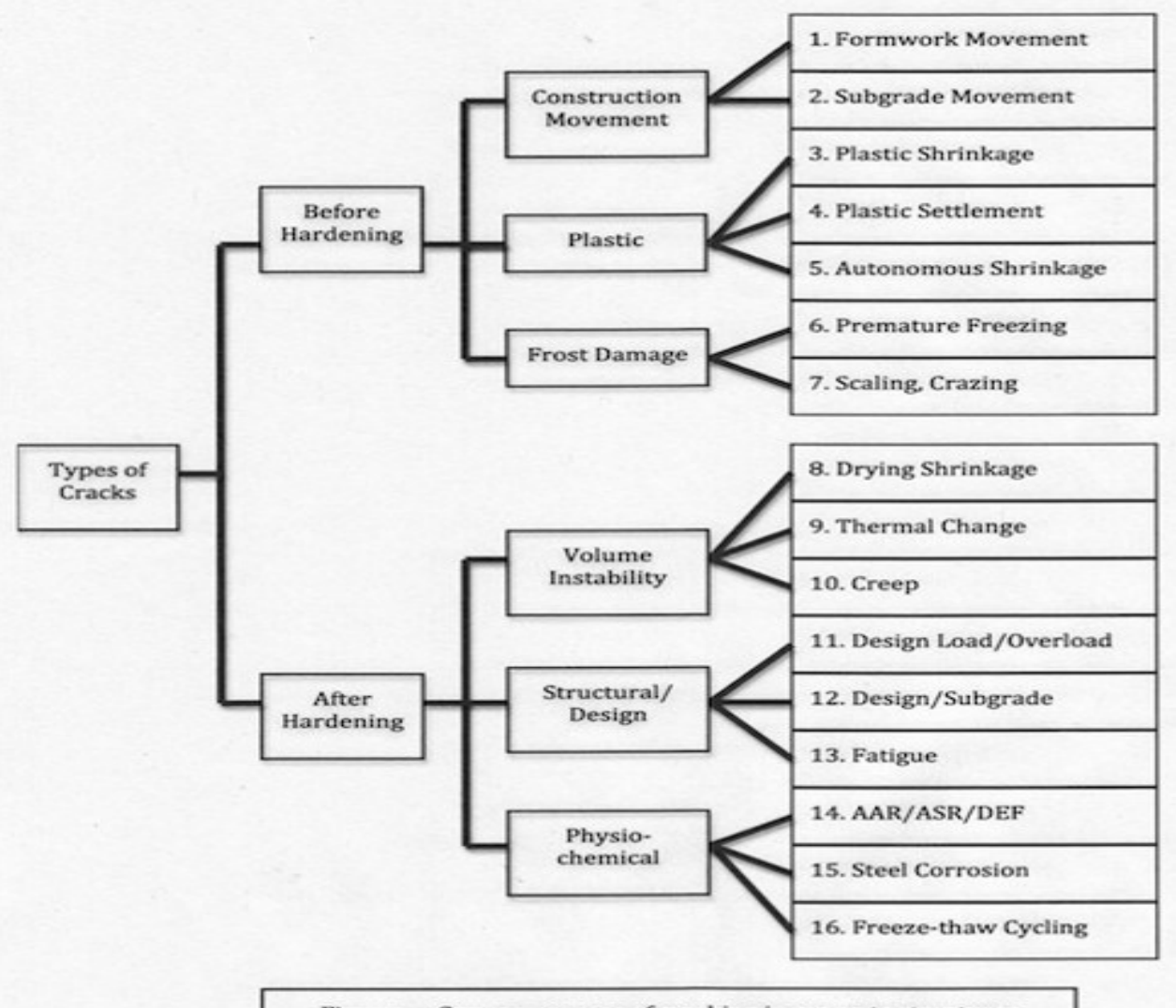

Figure Common causes of cracking in concrete structures

Fig.1: Types of Cracks (Shereef MI, Civil Digital.com, K.S.R. College of Engineering)

REVIEWING THE RECORDS AND GENERAL I' individual crack can run in a diagonal, longitudinal, TERMS ASSOCIATED transverse, vertical, or horizontal direction

Construction documents are typically filed before the permits for construction are issued. In the case of concrete construction, reviewing original documents and a paper trail over the history of the structure is one step in a thorough evaluation. These records that should be available for consideration:

- Design documents

- Plans, Specifications

- History reports, Inspection reports

- Site inspection results, Laboratory test records

- Concrete records on the materials used in construction and the batch plant

- Instrumentation documents

- Operation reports, Maintenance reports

- Monument survey data

\section{Isolation cracks}

Isolation cracks appear as individual cracks. This type of cracking indicates tension on the concrete. The tension is usually perpendicular to the cracks. An
Crack depth: Crack depth is categorized into four terms: surface, shallow, deep, and through. Crack width: Crack width ranges from fi ne to medium to wide. Fine cracks are typically less than 0.04 inch wide. A medium crack would be between 0.04 to 0.08 inch. Wide cracks exceed 0.08 inch.

\section{Crack activity}

Crack activity has to do with the presence of a particular factor causing a crack. Determining crack activity is necessary to determine a mode or repair. If the cause of a crack is causing more cracking, then the crack is active. Any crack that is currently moving is considered active. If a specific cause for a crack cannot be determined, the crack must be considered active.

\section{STRUCTURAL HEALTH MONITORING/ STRUCTURAL WELLBEING}

The way toward actualizing a harm location and portrayal procedure for building structures is alluded to as Structural Health Monitoring (SHM). Here harm 
is characterized as changes to the material as well as geometric properties of a basic framework, including changes to the limit conditions and framework network, which unfavorably influence the framework's execution. The SHM procedure includes the perception of a framework after some time utilizing intermittently examined dynamic reaction estimations from a variety of sensors, the extraction of harm touchy highlights from these estimations, and the measurable examination of these highlights to decide the present condition of framework wellbeing. For long haul SHM, the yield of this procedure is occasionally refreshed data in regards to the capacity of the structure to play out its proposed work in light of the unavoidable maturing and corruption coming about because of operational conditions. After extraordinary occasions, for example, quakes or impact stacking, SHM is utilized for quick condition screening and intends to give, in close continuous, solid data with respect to the honesty of the structure.

The SHM issue can be tended to with regards to a measurable example acknowledgment worldview. This worldview can be separated into four sections: (1) Operational Evaluation, (2) Data Acquisition and Cleansing, (3) Feature Extraction and Data Compression, and (4) Statistical Model Development for Feature Discrimination. When one endeavors to apply this worldview to information from certifiable structures, it rapidly winds up evident that the capacity to rinse, pack, standardize and combine information to represent operational and natural changeability is a key usage issue while tending to Parts 2-4 of this worldview. These procedures can be actualized through equipment or programming and, all in all, some blend of these two methodologies will be utilized.

Regularly known as Structural Health Assessment (SHA) or SHM, this idea is broadly connected to different types of foundations, particularly as nations everywhere throughout the world go into a much more prominent time of development of different frameworks running from scaffolds to high rises. Particularly so when harms to structures are concerned, it is vital to take note of that there are phases of expanding trouble that require the learning of past stages, in particular:

1. Detecting the presence of the harm on the structure

2. Locating the harm

3. Identifying the kinds of harm

4. Quantifying the seriousness of the harm
It is important to utilize flag preparing and factual characterization to change over sensor information on the infrastructural wellbeing status into harm data for appraisal.

Operational assessment starts to set the impediments on what will be checked and how the observing will be proficient. This assessment begins to tailor the harm distinguishing proof procedure to highlights that are exceptional to the framework being observed and tries to exploit interesting highlights of the harm that will be recognized.

\section{Information obtaining, standardization and purifying}

The information obtaining part of the SHM procedure includes choosing the excitation techniques, the sensor writes, number and areas, and the information securing/capacity/transmittal equipment. Once more, this procedure will be application particular. Monetary contemplations will assume a noteworthy part in settling on these choices. The interims at which information ought to be gathered is another thought that must be tended to.

\section{Highlight extraction and information Collection}

The region of the SHM procedure that gets the most consideration in the specialized writing is the recognizable proof of information includes that enables one to recognize the undamaged and harmed structure. Intrinsic in this component choice process is the buildup of the information. The best highlights for harm distinguishing proof are, once more, application particular.

The operational usage and analytic estimation innovations expected to perform SHM create a greater number of information than customary employments of basic elements data. A buildup of the information is beneficial and fundamental when examinations of numerous capabilities got over the lifetime of the structure are imagined. Likewise, on the grounds that information will be procured from a structure over an expanded timeframe and in an operational situation, vigorous information diminishment systems must be produced to hold include affectability to the auxiliary changes of enthusiasm for the nearness of ecological and operational inconstancy. To additionally help in the extraction and recording of value information expected to perform SHM, the factual noteworthiness of the highlights ought to be described and utilized as a part of the buildup procedure. 


\section{Measurable model improvement}

The segment of the SHM procedure that has gotten minimal consideration in the specialized writing is the advancement of measurable models for separation between highlights from the undamaged and harmed structures. Measurable model advancement is worried about the execution of the calculations that work on the separated highlights to evaluate the harm condition of the structure. The calculations utilized as a part of factual model advancement more often than not fall into three classes. At the point when information are accessible from both the undamaged and harmed structure, the measurable example acknowledgment calculations fall into the general arrangement alluded to as regulated learning. Gathering order and relapse investigation are classifications of directed learning calculations. Unsupervised learning alludes to calculations that are connected to information not containing cases from the harmed structure. Anomaly or oddity location is the essential class of calculations connected in unsupervised learning applications. The majority of the calculations examine factual dispersions of the deliberate or inferred highlights to upgrade the harm ID process.

\section{Essential Axioms}

In view of the broad writing that has created on SHM in the course of the most recent 20 years, it can be contended that this field has developed to the point where a few key adages, or general standards, have emerged.The maxims are recorded as takes after:

- Axiom I: All materials have natural flaws or imperfections;

- $\quad$ Axiom II: The appraisal of harm requires a correlation between two framework states;

- $\quad$ Axiom III: Identifying the presence and area of harm should be possible in an unsupervised learning mode, yet recognizing the sort of harm display and the harm seriousness should by and large just be possible in a directed learning mode;

- Axiom IVa: Sensors can't quantify harm. Highlight extraction through flag handling and measurable classification is important to change over sensor information into harm data;

- Axiom IVb: Without canny element extraction, the more touchy an estimation is to harm, the more delicate it is to changing operational and ecological conditions;

- Axiom V: The length-and time-scales related with harm start and development direct the required properties of the SHM detecting framework;

- Axiom VI: There is an exchange off between the affectability to harm of a calculation and its commotion dismissal ability;

- Axiom VII: The measure of harm that can be identified from changes in framework progression is contrarily corresponding to the recurrence scope of excitation.

\section{Components of SHM}

SHM System's components include: Structure, Sensors, Data securing frameworks, Data exchange and capacity system, Data administration. Data understanding and analysis:

\section{System Identification}

2. Structural model refresh

3. Structural condition evaluation

4. ClPrediction of residual administration life

\section{NDT Used in the Study Area}

The damage assessment can be done through destructive, semi destructive or partial destructive techniques. The methods and techniques adopted may be field based or laboratory based. NDT is the damage assessment method at field or site which reveals the suitability of the structure to be used in future. Vaiuor techniques are Rebound Hammer, Ultrasonic pulse velocity meter, Rebar Locator, Corrosion meter, Penetration resistance, Pullout or pull off tes, core cutting. In the present study visual inspection followed by rebound hammer and corrosion meter were used to analyze structures. Rebound hammer values were very less and the structure was found unsuitable for the rehabilitation or repair and it was noted that demotion of structure should be the best way to adopt. Also construction of various new building blocks can be done to fulfill requirements. Basically rebound hammer is used to evaluate strength. Spring driven mass strikes the concrete surface and rebound distance represents R-Value. Surface hardness is evaluated and strength is estimated from the calibration curves having some limitations. 


\section{RESULTS AND CONCLUDING REMARKS}

Structural health must be maintained and monitored on time to time basis. Structural health monitoring is the tool which is suitable for the prevention of structural unsafety. Also prevention, checking and repair are main facets of the maintenance. The building must be checked using NDT Techniques for evaluating its strength. One yearly report of structural monitoring must be prepared for the building used as a long term. Corrosion is the gradual deterioration which is caused by the chemical aggressive attack. It has to be checked after every monsoon season because it creates main problem in any building. Appropriate visual survey must be carried out quarterly of six monthly basis. Also the methods must be adopted to repair and rehabilitation only if strength is high and building is functionally unsuitable for serviceability requirement. But is building is unsafe for both criteria then it should be demolished as early as possible to quantify its possible future damage of itself and other buildings.

\section{REFERENCES}

1. R. Dodge Woodson,(2009),"Concrete Structures Protection, repair and rehabilitation", 2009, Elsevier Publisher.

2. Condition Assessment of Buildings for Repair and Upgrading Prepared under:-GoI-UNDP Disaster, Risk Management Programme, National Disaster Management Division, Ministry of Home Affairs, Government of India, New Delhi, June 2007.

3. Hand Book and Maintenance Manual on Repair and Rehabilitation of RCC Buildings, 2012Published By Director General (Works),Central Public Works Department, Government Of India, Nirman Bhawan.

4. Abhijitsinh Parmar, (2014),"Repairs And Rehabilitation Of Structures", Mahajan Publishing house.

5. P.I. Modi, C.N. Patel,(2015), "Repairs and Rehabilitation of Structures", PHI Publishers. 